DOCUMENTOS 


\section{CARTAS FAMILIARES DE FERNANDO VII}

\section{Gregorio Cervantes Martin}

La biografía de Carlota Joaquina está aún por escribir. Lo que hasta ahora se ha dicho se basa más en la fantasía y la parcialidad que en una investigación seria. Falta un estudio que analice su vida pública y privada basándose en una meticulosa investigación y no en la leyenda. Sus relaciones con su hermano Fernando VII son poco menos que desconocidas. No obstante, pueden obtenerse importantes datos de la correspondencia de Carlota con el monarca español, que trataba a su hermana con el mismo despotismo que a sus subditos, como se desprende de las cartas aquí reproducidas.

Carlota, que vivía en Río de Janeiro con su esposo Juan desde que dejaran Portugal escapando de Napoleón, había propuesto a sus hijas María Isabel y María Francisca como esposas de Fernando y de su hermano Carlos. En la carta del 17 de abril de 1815, Fernando, que sin duda había decidido ya en favor del matrimonio, se deshace en agradecimientos por lo mucho que Carlota ha hecho por la valerosa nación española ("excepto algunos pícaros que nunca faltan") y se considera indigno de tener una hermana tan buena como ella. No menciona nada del matrimonio, limitándose a decir que sus sobrinas le han gustado mucho y espera verlas pronto. En cuanto a su hermana, promete hacer lo imposible para sacarla del Brasil, un país tan perjudicial para su salud. El 3 de mayo ya se había decidido la boda, pedido las dispensas al Papa y se preparaban los barcos para traer las novias a España, si bien la nación no estaba para gastos. Fernando que no ha visto personalmente a su novia - se siente locamente enamorado e incapaz de esperar hasta ver realizado su matrimonio.

En la carta del 12 de junio vemos un Fernando diferente, más parecido a cómo nos lo ha pintado la historia de su vida. Ya parecen haberse calmado sus impulsos amorosos, pues no trata de su boda ni de su futura esposa una sola vez. Comienza su carta - que sólo firma, dice, por estar muy ocupado - en el mismo tono sensiblero y hipócrita de las demás. Lo que pretende Fernando es usar a su hermana para que convenza a la Corte portuguesa a intervenir en favor de España contra los rebeldes de América. La pacificación de América, dice Fernando, es un interés comúm, pues, a la larga - y hay que reconocer que no estaba muy equivocado en esto - el ejemplo de las colonias españolas influirá en las portuguesas. De ahí el mutuo interés en evitar tales precedentes. Las familias reales de Portugal y de España, agrega Fernando, no pueden mirarse más que como una sola; y él, para probar su buena fe, está dispuesto a devolver la plaza de Olivenza. A cualquiera se le ocurre que hubiera sido mucha mejor buena fe devolver la plaza en otras circunstancias. Así lo vio el autor del artículo aquí reproducido (hay una copia del mismo unida a las cartas), quien advierte que el fin de Fernando al casarse con la hija de Carlota es implicar a Portugal en la lucha contra las colonias españolas. 
La carta del 21 de junio la escribe otra vez el novio impaciente, pero el 14 de octubre no hay tiempo para amores. Los problemas políticos en América son la única preocupación de Fernando. Villalba, su enviado ante la Corte portuguesa, se había entrevistado con los rebeldes del Plata proponiéndoles un pacto, lo que suponía de hecho reconocer otro gobierno. Fernando propone a su hermana que lo revelará.

Por si eso fuera poco, las tropas que luchaban en el Perú se encontraban sin municiones ni armas, que estaban detenidas en Río abordo de la corbeta Abascal. Fernando, como ahora se encuentra otra vez necesitado, confía todo al amor de su hermana para que las municiones lleguen a Lima; pero piensa que Carlota está siendo mal aconsejada por Felipe Contucci, el famoso personaje amigo de José Presas.

Interesante en nuestros días es la opinión que tenía Fernando de las mujeres. A juzgar por lo que dice, su esposa es un ángel porque hace todo lo que él quiere, no es voluntariosa, es muy obediente y sólo desea darle gusto en todo. Es por lo tanto imposible, dice Fernando, que haya mujer más dócil (carta del 21 de enero de 1817). Lástima que la unión con María Isabel no tuviera políticamente los mismos resultados. Cuando los portugueses lucharon por fin contra los pueblos del Plata - que era lo esperado por Fernando al casarse - no fue como aliados, sino como conquistadores, que era lo que Fernando no había esperado y le desesperaba, "porque nadie ha pensado, que al dar un Soberano su hija a otro, le ocupe sus estados" (misma carta). ${ }^{1}$

Podemos obtener de estas cartas muchos más datos sobre la vida pública y privada de Fernando. En la del 20 de abril de 1817 se muestra otra vez desconsiderado y cruel con su hermana. Ya no se acuerda de la firme promesa que hiciera el 15 de abril de 1815 de sacarla del Brasil. A la ayuda que Carlota le pide para distintos asuntos, contesta ruda y tozudamente que no puede hacer nada. ${ }^{2}$

Madrid 17 de Abril de 1815

Mi muy amada Hermanita mia de mi alma, Carlota de mi corazon. Me aprovecho de esta ocasion para escribirte, diciendote que Vigodet y Fr. Cirilo Alameda me han entregado tus cartas, dos del 6 de Noviembre, una del 9, y dos del 30 de dho. Noviembre, como tambien una exposicion, con los respectivos documentos de todo lo q. has trabajado en favor mio, y en beneficio de una Nacion tan fiel y valerosa como la Española (excepto algunos picaros q. nunca faltan) no dudaba yo de lo que tú me estimas, y de que no soy digno de tener una Hermana tan virtuosa como tú. Tambien he visto el plan de la revolucion de America q. me has remitido, el qual demuestra bien la perfidia y maldad de esos perversos insurgentes, gracias á tus desvelos y cuidados, que en quanto cabe han podido detener ese torrente.

Me ha entregado tambien Fr. Cirilo los retratos de tus hijas y mis sobrinas que me han gustado mucho, y me ha alabado lo buenas que eran, y la buena educacion q. han recibido, no lo he dudado nunca, pues tienen una buena Madre; espero verlas pronto, y sacarte de ese pais q. es tan perjudicial à tu salud; ya puedes considerar que no haré yo por una Hermana à quien tanto amo, $y$ à quien debo tantos favores.

No tengo mas tiempo, y asi manda quanto gustes à este tu apasionado herm.

Fernando

[Rubricado]

P. D. Disimularás la mala letra, y el estilo tan macarronico. 
undisis 17 re ctibil re 1815 .

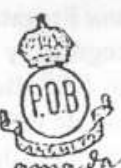

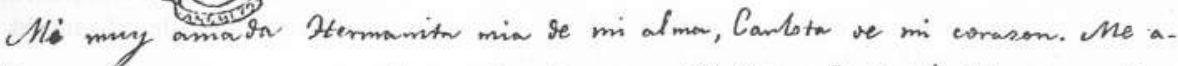
provecho re cstor ocasion para eseritirte, Diciemioter gue Vigolet y Ir. Civilt' Alameta me ham

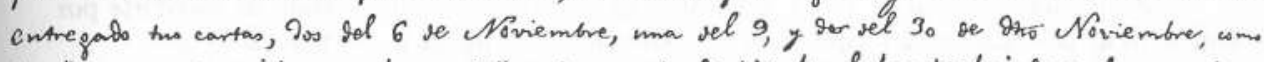

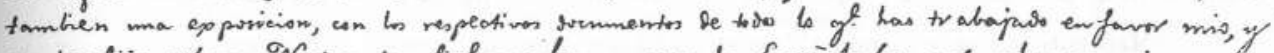

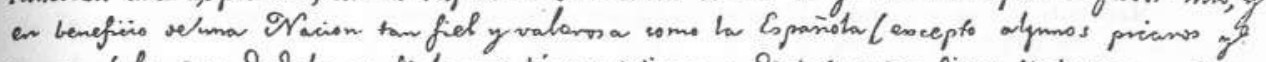

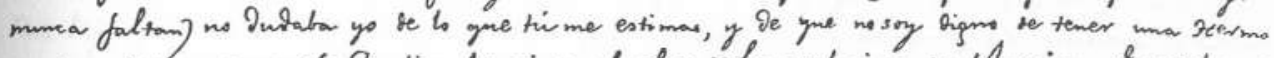

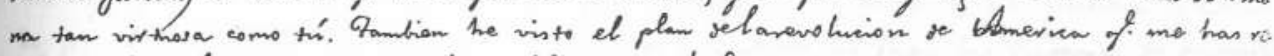

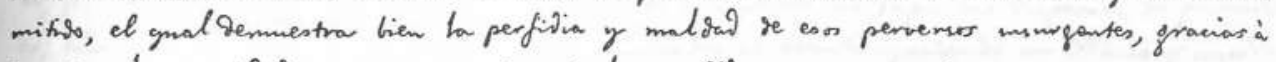
tus resvelos y cuilatos, gue en gnanto cabe han potilo contener ese torvernte.

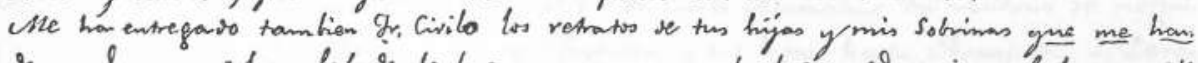

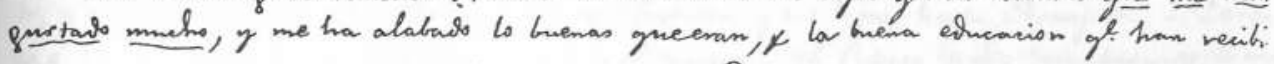

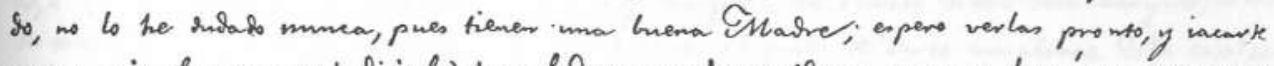

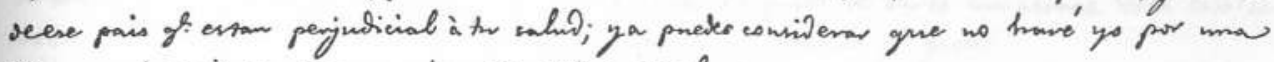

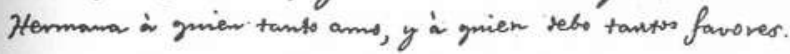

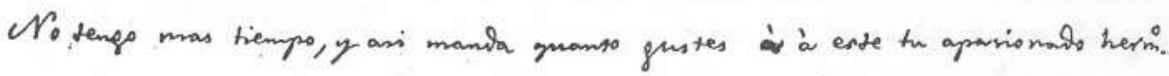

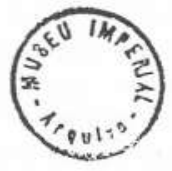

Germands

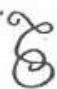

P. 9. Sisinumbarás la maka letra, y el ectilo tam macorromio. 
Madrid 3 de Mayo de 1815

Querida Carlota mia de mi vida, hermanita mia de mi corazon. Con grande gusto te

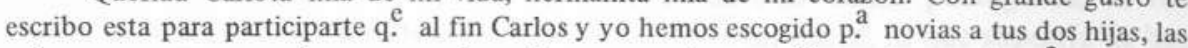
mismas que nos proponias; ya no sosiego ni un momento, ya quisiera estar casado; p. mediante Dios, no se tardará mucho; ya se han pedido al Papa las dispensas de parentesco; todo esto se hace con el mayor sigilo. En Cadiz se están disponiendo un Navio y una Fragata, en los q. irán à buscarte Vigodet, y el p. Fr. Cirilo Alameda. Tu vendrás de incognito, y viajarás baxo el titulo de Duquesa de Olivenza y sus hijas, hasta Aranjuez, S. Lorenzo, ó S. ${ }^{\mathrm{n}}$ Ildefonso, p. esto depende del camino q. traigas, y del Puerto donde desembarques; à uno de estos tres puntos, te iremos à buscar, $y$ tendremos el gusto de darte un abrazo. Todo esto se hace de esto modo, p. q. esté mas secreto, y porque no estamos p. gastos.

Pudiendose retardar la salida del Navio, noquiero perder esta ocasion de escribirte por conducto de D. Joaquin Severino Gomez, Secretario de la embajada de Portugal.

Mantente buena, y manda q. ${ }^{\text {to }}$ gustes à tu afectisimo hermano, y futuro yerno

Fernando

[Rubricado]

Madrid 15 de Mayo de 1815

Querida Carlota mia de mi corazon, hermanita mia de mi alma. Ya se cumplieron tus deseos: con esta fecha escribo à tu marido para pedirle por esposa mia à tu hija Maria Isabel, y para serlo de Carlos à tu hija Maria Francisca. Me refiero en todo à lo que te digo en la otra carta mia, que lleva tambien Severino Gomez, solamente que siendo muy largo habilitar el Navio y la Fragata, he dispuesto que se ponga corriente solo esta à la mayor brevedad, en la q. $\mathrm{e}^{\mathrm{a}}$ irán Vigodet y Fr. Cirilo, siguiendose sin embargo el apresto del Navio, para que marche quando esté listo.

Carlos te envia un retrato suyo; el mio no se ha podido acabar, y lo enviaré con Vigodet, siento no remitirtelo ahora, pero no se ha podido remediar.

Te encargo de nuevo el sigilo sobre este asunto, pues asi habrá menos obstaculos para tu venida, $\mathrm{y}$ haciendola tú como particular se originarán menos gastos q. no estamos para ellos.

En cuanto à los contratos matrimoniales, ya le digo à tu marido que se hablará de ellos, quando esté mas publico.

Mantente buena, y procura cuidarte, para que pueda tener el indecible gusto de darte un abrazo tu afectisimo hermano 
Documentos

135

Thowis 39 e Snayo te 1815 .

$(P .0 .8)$

Inerila Cailota mia de mi vila, hermantita mia de mi corason. Con granta gan: to te eserrilo esta para participarte $g^{2}$ al fir Carlos y ya hemos escogito pa novios àtus Sos hijas, las mismas gue nos praponias; ya no sosiego ni mo momento, ỹ gaisieva estar casa

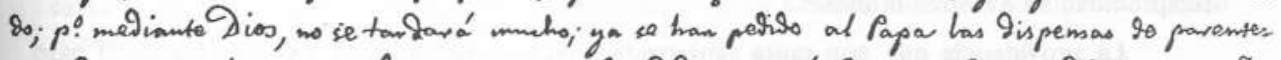

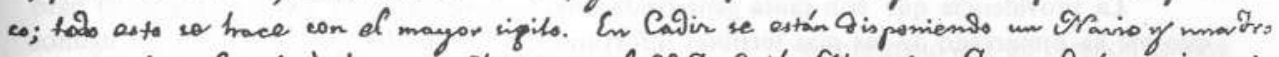

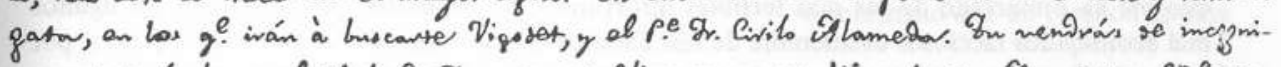

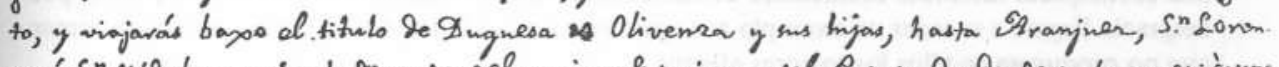

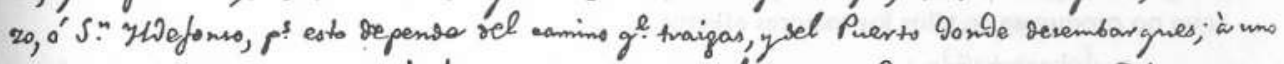
se estos tres puntos, te ivomos a buscar, y tembremos el gusto se Farte un abraso. Dodo esto se hace be este mulo, $p^{a} g^{e}$ esté mas secreto, y porgue na estanos $p^{2}$ gastos.

Putiemase retardar Lasalita sel Pavio, no gniere perser esta ocasiom re escri-

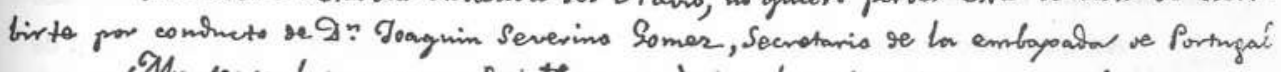

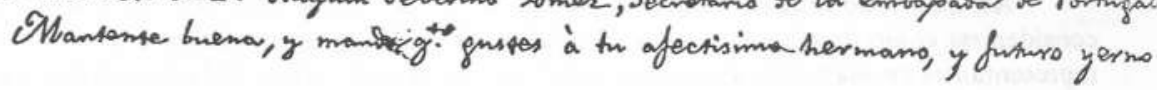

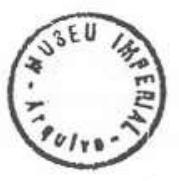

Germano. 
Madrid a 12 de Junio de 1815

Mi mas amada hermana he recibido con el mayor placer tu expresiva carta de 23 de Enero proximo pasado, y su contenido que manifiesta bien tu empeño en promover mis intereses en esa preciosa parte de mis dominios, ha excitado toda la ternura de mi corazon y mi mas sincera gratitud. La pintura que me haces de su estado, tus prudentes advertencias para que desconfie de la mision del Gobierno revolucionario de Buenos Ayres cometida a dos personas las mas sospechosas, las ideas que me das de los partidarios de Artigas y Ortogues que convienen con las que yo ya tenia, el modo en que crees que se les puede auxiliar, los medios de que piensas valerte para cooperar a la pacificacion de esas hermosas Provincias, y la delicadeza con que provienes todo lo que pueda entorpecer demostrada en las observaciones que me haces sobre la conducta de mi Encargado Villalva, con otros tantos testimonios de tu amor constante, $y$ de la parte activa y eficaz q. te tomas en mi prosperidad, y en la de mis Reynos.

No me obliga menos que tu decidido afecto la franqueza con que para mas acreditarmele llamas mi atencion sobre todos estos puntos que son los que abraza tu carta; y me faltaria yo á mi mismo si no usara de igual confianza para manifestarte a ti el mio, y ofrecer a tu vista la reciprocidad de nuestros intereses.

La providencia que con tanta generosidad me ha prodigado tal linaje de bienes al paso que me ha preservado de los mas terribles infortunios, no permitira que el extravio de algunos mal aconsejados facciosos desmembre de mis Estados esas tan apreciables Posiciones; pero si por desgracia llegase a suceder un exemplo tan seductor, y tan á la faz de los tuyos, es bien de temer que no produgera en ellos los mejores efectos.

Estan nuestros intereses tan intimamente unidos, hermana mia, que con dificultad podra ofenderse á los unos sin que los otros se resientan: por esta razon, y por el enlaze [sic] de las coronas que es de tal naturaleza que forma una verdadera identidad de relaciones, debe mirarse no solo como de conveniencia, sino como de necesidad el que vivan sinceramente hermanadas.

Asi que, todo influxo dirigido a introducir o mantener la discordia, no puede menos de considerarse como desafecto en este punto. Esta observacion me da margen á indicarte que mis representantes en esa Corte al paso que estan muy reconocidos a las bondades y distinciones con que son honrados por ti, y por el Principe tu esposo, siempre se quexan del poco abrigo que hallan sus reclamaciones en el Ministerio, conducta bien contraria á la que se tiene aqui con todo lo que dice relacion al Portugal.

Yo deseo, querida hermana, que se restablezca aquella franqueza é intimidad que se mantubo entre las dos Cortes durante el reynado de augusto Abuelo. Por mi parte te aseguro q. nada se omitira para llegar a este caso que tanto importa a dos familias que deben mirarse como una misma por la identidad de sus intereses, y por otros muchos titulos.

Aunque de la fidelidad y celo de Villalva se tienen repetidas pruebas no me aparto de tu sentir en que debe desaprobarse su conducta en haber propuesto al Gobierno revolucionario de Buenos Ayres la suspension de Hostilidades de que me das parte, y él tambien avisa. Esto paso poco meditado, asi como la novedad que has advertido en su mucha politica desde la llegada de los comisionados de aquel Gobierno, no extrañare tampoco que sea fruto de las seduccion y arterias de estos Sujetos, cuyas miras pueden ser bien las que me insinuas de ganar tiempo para asegurar su defensa: por descontado siempre las Proposiciones de Villalva son una especie de acto de reconocimiento que solo tiene lugar con los Soberanos legitimos, y no con unos reveldes a quienes no se debe convidar sino con la clemencia de su Rey en caso de humillarse de buena fee a implorarla. Asi se lo hago entender a dho. Encargado, y que en asuntos de gravedad de esta naturaleza proceda siempre de acuerdo contigo.

Si no se nombra para esa Corte un ministro representante con el caracter que no corresponde a ntra. estrecha alianza é intimas relaciones, y qual tu me dices convendria, no es el motivo que la proximidad de su deseada traslacion a Lisboa. 
En orden a los auxilios solicitados a nombre de Artigas y de su segundo Ortogues, tus mismos Papeles convencen a qualquiera luz que se les mire de la necesidad de prestarselos. Yo he tomado algunas medidas tambien, $y$ con el objeto igualm. te $^{\text {te }}$ que no se arrepientan del partido que han abrazado al parecer de buena fee. Esa Corte que no puede olvidarse de la garantia en favor de la conservacion de la America meridional, está en el caso de ayudar a la España por todos medios en su empeño de reducir a los reveldes, lo que debe mirar ese Gabinete como un interes comun, $y$ a lo que espero que tu, hermana mia, influiras eficazmente.

Mientras tanto yo no olvidare tampoco nada de cuanto pueda contribuir a tus satisfacciones, y realizar los deseos de esa Corte, con particularidad los dirigidos a la devolucion de la Plaza de Olivenza; Baxo el supuesto que en este asunto, como ya tengo indicado oficialmente, no deben intervenir otras Potencias: debera si terminarse por un tratado y acuerdo de familia con reciproca satisfaccion.

Si lo creyeses conveniente podras hacer ver esta carta al Principe tu esposo para que conozca mi pronta disposicion á mantener la mayor intimidad y franqueza, como así bien á terminar el importante punto de la cesion de la referida Plaza.

Por mi detencion a contestarte menudamente sobre todos los articulos de tu apreciable carta conoceras el gusto con que la he recibido, y el que habra de tener siempre con igual ocasion

tu hermano que de corazon te ama

Fernando
[Rubricado]

No escribo esta de mi puño por estar muy ocupado.

Madrid 14 de Junio de 1815

Querida Carlota mia de mi vida, hermanita mia de mi alma. Me aprovecho de la salida de tu criado Machado para esa, para escribirte estos quatro renglones, diciendote que estoy muy satisfecho de la conducta que ha tenido aqui: se conoce que es muy fiel, y yo estoy muy contento de él.

Te agradezco mucho el fino de Madera que me has enviado, el qual es muy bueno y exquisito: tambien hemos comido los palmitos, que siempre conservan el sabor à la manteca rancia en que han venido embueltos, sin embargo se que se les ha limpiado muy bien; te doy muchas gracias por todo, asi como por la parte que tomas en mis intereses.

Te incluyo la adjunta nota que me ha dado Ardisson, tu haras de ella el uso q. creas conveniente.

Mantente buena, y no te olvides de tu apasionado hermano

Fernando

[Rubricado]

P.D. Adjunta vá una carta de Ramirez, que me ha pedido se la remita, cree q. es un hombre de bien y muy honrado, y la caxa de que habla me la ha entregado la misma noche q. yo le vi en Aranjuez, y la conservo en mi poder. 
Querida Carlota mia de mi vida, hermanita mia de mi alma. Ya llegó el momento tan deseado de que estuviese lista la fragata, y el de la salida de Vigodet y Fr. Cirilo (q. es el portador de esta). Te repito lo que te dixe en la que entregue à Severino Gomez, de que con motivo de que no estamos para gastos, y para que se guarde mejor el secreto, tu y tus hijas vendreis de incognito, y como unas particulares, baxo el nombre de Duquesa de Olivencia y sus hijas, hasta Aranjuez, Sn. Lorenzo, ó Sn. Ildefonso; pues eso dependerá del puerto donde desembarques, $\mathbf{y}$ del camino que tomes en llegando à España: en uno de estos tres puntos tendré yo el incomparable gusto de darte un abrazo, y tambien a mi novia: lo que es menester es que actives en cuanto puedas tu salida de Rio de Janeiro, para lo qual te pondrás de acuerdo con Vigodet, pues este lleva amplios poderes y facultades para hacer lo que tu le digas, porque nadie mejor que tú sabrá como se ha de gobernar este negocio.

Tambien te embio un retrato mio, que segun dicem todos está muy parecido, $\mathrm{y}$ al reverso tiene la cifra de mi nombre hecha con pelo. Como el pintor es tan pesado, no te puedo embiar mas q. un retrato, que no es para ti sino para mi novia, pues quando tu llegues verás el original, y ademas entonces te daré otro retrato.

Te participo tambien como Carlos y yo tenemos ya en nuestro poder las dispensas del Papa, y teniendo mucho que hacer, y no ocurriendo por ahora otra cosa, manda quanto gustes à tu apasionado hermano y futuro yerno que ansia por verte.

\section{Fernando}

[Rubricado]

P. D. Te incluyo copia de la que escribo al Principe tu marido.

\section{Copia}

Querido Hermano mio. Te repito lo que te dixe en la que llevo Severino Gomez, que hallandome en el caso de elegir compañera, que al paso q. estreche mas nuestra union, forme la felicidad de mis pueblos, he resuelto despues de un maduro examen pedirte p. esposa mia à tu hija D. M. Isabel Francisca, persuadido de las bellas qualidades que la adornan, y de q. será este enlace de tu aprobacion, y considerando q. mi Hermano Carlos se halla igualmente en edad proporcionada p. tomar estado, y q. desea tambien efectuarlo con tu tercera hija D. $\mathrm{M}^{\mathrm{a}}$ Francisca de Asis, de quien tiene iguales ventajosas noticias, te lo participo para tu satisfaccion, y él espera apruebes su eleccion.

Esta carta la lleva el General Vigodet, q. va acompañado del P. Fr. Cirilo Alameda: Dicho General va con amplios poderes p. tratar de este asunto, y yo le he autorizado p. q. de acuerdo con mi hermano active este negocio lo mas q. pueda. Tambien te digo q. p. ahorrar gastos, y p. q. sea esto q. ${ }^{\text {to }}$ antes, deseo q. mi hermana y sus hijas vengan de incognito, y como unas particulares (baxo el nombre de Duquesa de Olivenza y sus hijas) hasta Aranjuez, $\mathrm{S}$. Lorenzo, ó S. Ildefonso, p. eso dependerá del camino q. tomen en desembarcando en España: à qualquiera de estos tres puntos las saldré yo à recibir con todo el aparato y decoro que se las debe.

Asi mismo te doy parte de q. ya nos ha enviado el Papa las dispensas del parentesco, con q. ya ves q. hay mucho adelantado.

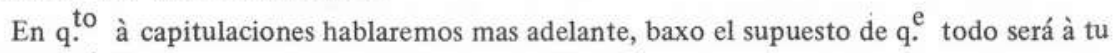
satisfaccion, ó si quieres, puedes tratar de ello con Vigodet.

Mi Hermana te enseñará el retrato q. yo la envio, y espero que no te disgustará, asi como todo lo q. se trate en punto à matrimonio, q. es quanto desea tu herm. q. de corazon te estima $=$ Fernando $=$ Madrid 21 de Junio de 1815. 
Mainin 20 ge Timio re 1815.

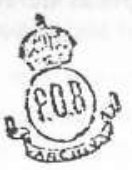

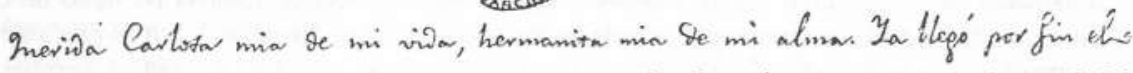

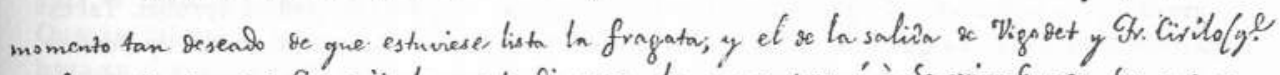

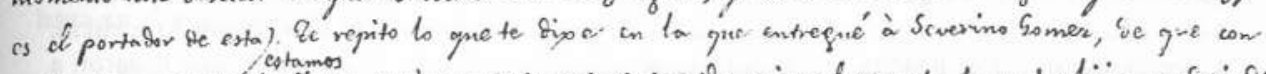

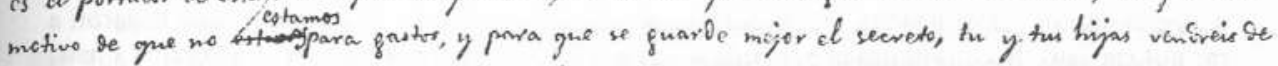

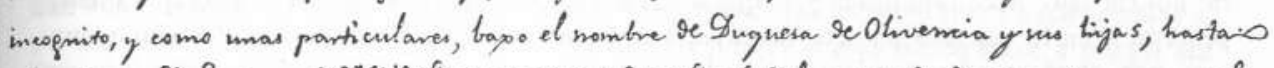

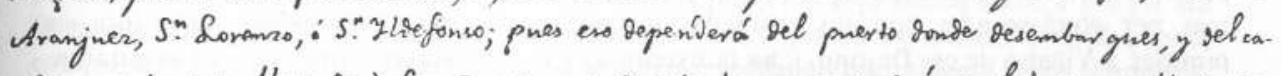
mino que tomes en Ileganio à España: in uno be estas tres puntostonaré yo el incomparable guitio

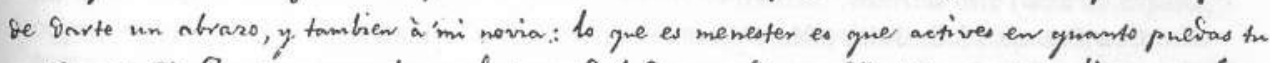

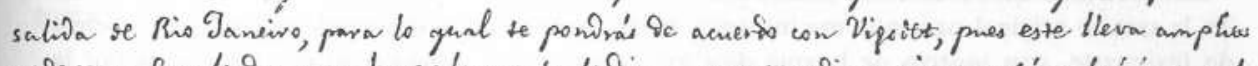

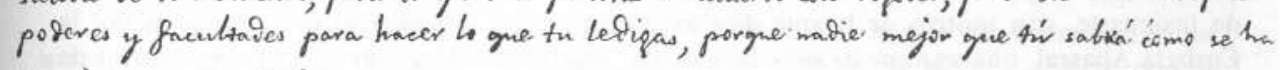
De gobermar este negocio.

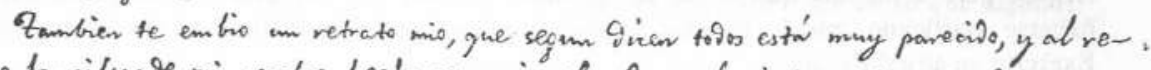
verse tiene la cifra te mi nombre hechn con mi pelo. Como el pintor estan pesabo, no te pu

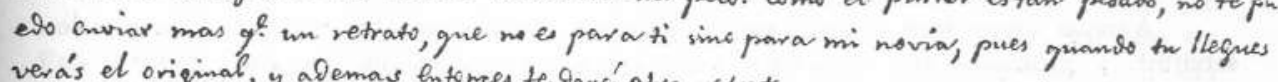
verás el original, y ademas entomes te oavé abro retratio.

Te participo tambien como Carlos y yo tenemos ya en miestro posier has cispensas bei Papa; y terienivo mucho que haces, y no ocusirienis por ahora otra cosa, mania granto gustes à th apasionaio heimano y futuro yeurno gue ansia pos verte

P.9. Te meluyo copia be la gue escribo al Prinerpo tor mavito.
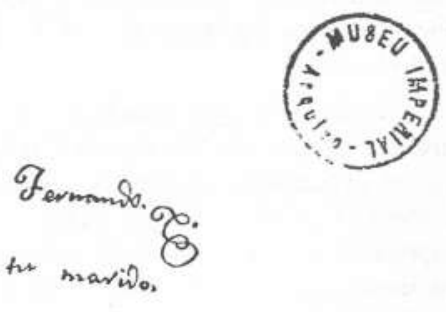
Madrid a 14 de Octubre de 1815

Amada hermana Carlota, he recibido con el mayor gusto tus apreciables cartas de 20 y 30 de junio proximo pasado con las duplicas de 10 , y 25 de Abril, y los documentos que las acompañaban y en todo veo tu interes y tus desvelos en mi obsequio, de lo que puedes estar bien cierta q. no me desentendere jamas.

Ya anteriormente te he dicho que aunque de la fidelidad de Villalva tengo pruebas repetidas, como asi bien de sus buenos deseos, y sana intencion, todavia no dexo de conocer que en algunos de los pasos que he dado ha procedido con ligereza, y sin la precaucion que corresponde a su caracter, [? ] lo que á ti te ha desazonado, y yo no he podido aprobar. Tal es entre ellos la conducta que observó con los Diputados del Gobierno revolucionario de Buenos Ayres quando estuvieron en esa Corte, y tal su Propuesta al mismo Gobierno de un Armisticio, ó suspension de Hostilidades. Qualesquiera que en esto fuesen sus miras, luego que llegaron a mi noticia estos hechos di orden para que se le hiciese entender mi desagrado, y para que a nada procediese en lo sucesivo sin acuerdo tuyo; y de todo te avisé para tu gobierno. Por esto, y aun mas por condescender con tus reiteradas instancias, y complacerte pienso seriamente en remover a Villalva de ese Destino, y no tardaré mas en realizarlo que lo que tarde en asegurarme del acierto en la eleccion del que le haya de suceder.

Con fha. de 18 de Julio ultimo escribe Villalva en los terminos que veras por la adjunta. Te la remito original para que me informes menudamente de su contenido no pudiendo menos de insinuarte, con motivo de lo que dice en quanto á la remesa de los dos mil fusiles por la Corbeta Abascal, que siempre ha sido de la mayor importancia el acudir al Peru con socorros de Armas, pero á medida que se ha ido pasando el tiempo se ha hecho tan urgente que de no haberse verificado, puede haberse seguido por lo menos la lentitud de los progresos de mi Exercito en aquel Reyno.

Aunque estoy bien seguro, amada hermana, de tus sinceros, y eficaces deseos de servirme, y promover mis verdaderos intereses en esos mis Dominios, tengo motivos de desconfiar de algunas de las personas que te rodean, y principalmente de D. Felipe Contucci. Sugetos de credito me han informado que abusa de tu bondad, y lo cierto es que la circunstancia de haberse hallado en Montevideo (en donde esta casado con una española de las mas insurgentes) exerciendo el espionage, ocupacion que le ocasionó la salida de aquella Plaza, debiendo haber venido á Cadiz en partida de registro por orden del gobierno, me hace temer sus malas intenciones, $y$ desear por tu bien y el mio que no le honres mas con tu confianza, y que le alejes de tu correspondencia, y de tu lado. Las razones de conveniencia mutua me hacen esperar que lo haras asi.

Quando te estoy escribiendo han llegado dos Diputados de Chille [sic] á darme parte, y el parabien del recobro de aquella Capital; y preguntados por el estado de mi Exercito del Peru, me han informado hallarse tan falto de fusiles que las tropas que forman la retaguardia en las acciones [? ] han tenido que figurarlos con palos, y con estacas. Esto, hermana querida, me hace empenarte de nuevo á que no se retarde mas la remesa de los dos mil fusiles que debiera haber conducido a Lima la Corbeta Abascal. Todo lo espero de tu amor, asi como tu, el Principe, y tu familia debeis tener igual confianza en el de tu mas amante y fino hermano.

Fernando

[Rubricado]

P. D. Te incluyo las dos adjuntas que acabo de recibir de Roma. ${ }^{3}$ 
Querida Carlota mia hermana mia de mi corazon. Seguramente dirás que te he olvidado, pues hace horror de tiempo que no te escribo, pero no creas que haya sido por falta de cariño, sino porque he tenido mucho que hacer, por lo qual siempre he encargado à tu hijas y mi querida Esposa Maria Isabel, que te enviara recados de mi parte, como lo ha hecho.

Cree, hermana mia, que cada dia estoy mas contento de haberme casado con tu hija, pues es un Angel, hace todo lo que yo quiero, no es voluntariosa, no tengo que reprenderla en la misma minima cosa, pues es de un genio muy obediente, y no desea mas que darme gusto en todo: en una palabra somos muy felices, y cada dia nos queremos mas, y parece que un genio se ha hecho para el otro. Ya está embarazada, de modo que para principios de Julio espero ser Padre. Quantas gracias te debo dar por haberme proporcionado tan buena compañera, es imposible que haya en el mundo mujer igual, ni mas docil.

Por lo que me dices de tu nieto, el Infante Don Sebastian, sobre su derecho al Priorato de San Juan, se vá á ver en la Camara de Castilla, pues yo no quiero perjudicar á nadie, porque si yo me decidiese por mi Hermano Carlos dirian que era porque el otro estaba lexos, y porque era Hermano mio, y si yo me decidiera por Sebastian, dirian que yo no atendia á mi Hermano, conque asi mejor es que lo decida un Tribunal: ademas hablando francamente como Hermanos, no tiene mucho derecho, ó por mejor decir ninguno, Sebastian, mientras esté fuera de España, como tu misma conoces, pues esta fue la mente de nuestro Abuelo: en fin veremos que rumbo toma.

Esta carta la lleva el Marques de Vallada, el qual te dirá lo que nos queremos, y que matrimonio tan feliz es el nuestro: esta carta va dentro de la de mi amor, y abierta, porque tengo mucha confianza en ella, pues se lo merece, porque es muy diferente de lo que algunos me habian dicho.

En quanto á la expedicion de los Portugueses al Rio de la Plata, es la mayor felonia que se puede dar, porque nadie ha pensado, que al dar un Soberano su hija á otro, le ocupe sus Estados; esta conducta es peor que la de Bonaparte, que al fin era un enemigo, y no era pariente: procura tú como Española, amante de tu Patria, y hermana mia, enderezar la cosa y remediarla en lo que puedas, pues esto no es mas que burlarse de mi y de la heroyca nacion Española, y los Portugueses se cubren de oprobio y de infamia: en fin en ti confio, que no te olvidarás de tu España, ni de un hermano que tanto te quiere.

Adios hermana mia de mi vida, procura cuidarte, y no teniendo tiempo para escribirte mas largo, cree que te estima de todo corazon tu afectisimo y apasionado hermano

\section{Fernando}

[Rubricado]

P. D. Te envio una caxita con Mosayes y brillantes para que tengas una memoria mia, ella no es una gran cosa, pero á lo menos es prueba de mi cariño.

Madrid 20 de Abril de 1817

Querida Carlota mia de mi vida, Hermana de mi corazon. Ahora que se proporciona ocasion de escribirte, con motivo de la salida del Conde de Casaflores para esa, me aprovecho para escribirte, y manifestarte el amor que te tengo, y que no me olvido de ti nunca, que si no te he respondido antes, no ha sido por falta de cariño, sino por falta de tiempo, y porque tenias noticias mias por medio de mi muy querida esposa Maria Isabel, á quien adoro entreñablemente, 
y que posee mi corazon: cada dia estoy mas contento con ella, pues me has proporcionado una buena compañera (de lo qual te viviré muy agradecido toda mi vida) que se desvive por mi, que no desea mas que darme gusto en todo, y sobre todo y lo mas apreciable que se ha hecho una verdadera Española, y que no mira mas que por los intereses de su marido, y por la tranquilidad y felicidad de la España.

Voy á contestar a todas tus cartas. En la $1^{\stackrel{a}{a}}$ fha. 15 de Octubre del año pasado me hablas de que yo sea mediador para que se verifiquen las bodas de tus hijas, te digo q. yo no me quiero meter en eso, pues bastante me he fastidiado de aguardar año y medio para la mia, y no quiero que á los demas les suceda otro tanto: tampoco sé yo como reducir a tu marido á que regrese á Lisboa, pues no sé sus intenciones, y tú que estás mas al corriente de todo puedes buscar medio de obligarle á q. lo execute.

En las de 10,11, y 16, contestas á la llegada de mi querida Maria Isabel á España, y en quanto á la P. D. q. me pones sobre el P. Cirilo, te digo que me parece un Religioso bueno y arreglado, he oido sus Sermones, y me han gustado. Me hablas sobre el proyecto de Fernandez Varela para introducir 100 mil quintales de tabaco: te digo q. esto no puede ser, pues no quiero perjudicarme, ni hacerlo á los demas.

En la de 22 me hablas sobre el casamiento de tu hijo Pedro, y que yo me interese con el Emperador para que no se verifique la boda hasta que hayas vuelto á Portugal: ya ves que esto es imposible, pues ya va á salir la novia, á quien deseo igual felicidad que la q. nosotros disfrutamos.

En la de 28 me dices que han llegado al Janeyro cartas que han escrito mi muger y su hermana á varias personas de esa, y que yo las diga que no escriban mas que á las personas que tu me citas; no sé que çartas puedan ser, pues yo veo todas las que mi muger escribe, y ella misma me las enseña, de modo que ya voy aprendiendo el Portugués á fuerza de leer todas sus cartas, las que van y las que vienen, con que asi no tengas cuidado, ademas de que ella es casada, y tiene mucha prudencia.

En la de 11 de Diciembre, como en otras, me dices que me entere de los oficios de Villalba, cree q. lo hago asi.

En la de 20 de Diciembre me avisas del estado de tu salud, y me recomiendas á la de Urrutia para Camarista; la tendré presente.

En la de 4 de Enero de este año me enteras del genio de mi amor, pues no sé llamar de otra suerte a mi dulce Maria Isabel, cree q. si envio las cartas, por ella, es porque tengo seguridad de ella, y de que no van á manos de su Padre; y asi esta va dentro de la suya, por ser ocasion mas segura, por llevarla Casa Flores.

En la de 14 me dice que tienes disipela; lo siente muchisimo, pues quisiera que no tuvieras la menor incomodidad, y asi deseo que quanto antes me avises de estar ya enteramente buena, pues puedes estar segura de que te amo entrañablemente.

En la de 27 de id. te quexas de no haber recibido carta mia; á esto ya te he respondido al principio.

Aqui tenemos la gran pena de que nuestro tio Antonio está muy malo, con una fuerte pulmonia, está á los ultimos, sacramentado desde el 16 del corriente, de modo que me temo mucho que se nos vaya.

Maria Isabel, sigue un metodo de vida muy arreglado y conveniente á su salud, de modo que aunque le han dado ya 6 accidentes desde que se ha casado, son mucho menores, y espero q. en pariendo se le quitarán. Ya está en el septimo mes, sigue muy bien y para Julio pienso ser Padre: de manera que creo se ha hecho embarazada la noche q. nos casamos.

Procura disuadir á tu marido de la invasion que ha hecho, pues es una villania y felonia, que le hace muy poco honor, y echa un borron á todo lo bueno que haya hecho en su vida, sobre todo en la circunstancia de nuestras bodas. 
Adios Hermanita mia de mi corazon, cuidate mucho, y creeme tu afectisimo Hermano que de corazon te quiere

Fernando

[Rubricado]

Querida Carlota de mi vida, Hermanita mia de mi corazon. Me alegro que estés buena, nosotros tambien lo estamos, gracias á Dios. No creas que es por falta de cariño el no haberte escrito hace tanto tiempo, ni que me haya olvidado de ti, sino que no tengo tiempo suficiente, pues me falta aun para lo mas preciso; con que asi no me culpes de omiso, ademas muchas veces que te escribe mi mujer no lo hago yo, porque en el echo de escribirte ella ya tienes noticias mias.

Mi hija sigue muy bien cada vez se va poniendo mas blanca gorda y hermosa, de modo que es un gusto ver como la aprovecha la leche de su Madre, la qual la tiene muy abundante.

Cree que hemos estado muy acongojados quando el parto de Maria Isabel, pues despues de haber estado padeciendo durante quarenta y ocho horas, por la impericia del Comadron, dixo este que tenia dos en el vientre, uno muerto y otro vivo, hasta que se llamo al primer Cirujano de Cámara Don Agustin Frutos [?], el qual dixo que el parto venia bien, que la criatura estaba viva, y que el no acabar de salir era porque habia unas membranas que lo impedian; las separó, y en dos horas y media despachó, habiendo nacido á las dos y diez minutos de la madrugada del 21 del pasado echado las [?] á poco tiempo con mucha facilidad.

Te incluyo dos cartas que me han enviado de Roma, y tambien te envio una memoria de nuestro Tio Antonio, que esté en gloria, que me alegraré sea de tu gusto.

Adios Hermanita mia cree que te quiere de todo corazon tu apasionado Hermano

Fernando

[Rubricado] 
Vllawin 19 oe Septiemtre retit:?

0 593

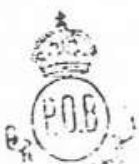

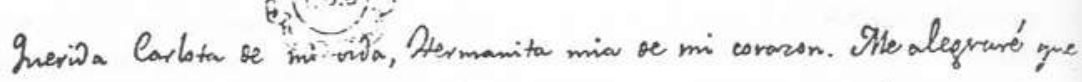

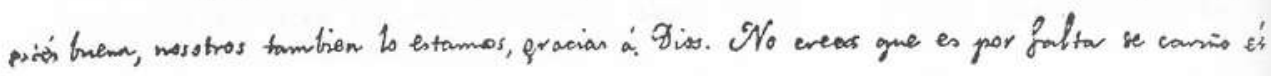
$\rightarrow$ haberte escrito hace tanto tiemps, ni gre me haya olvinaso ge it, sina gue no tenge tiem* inficiente, pres me falta anm para to mas preciso; congue asi no me culpres se ouniso

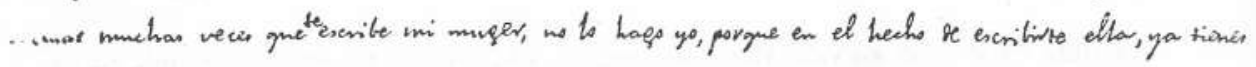
- nowar mias.

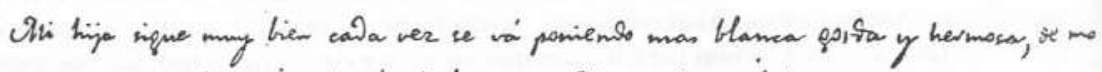

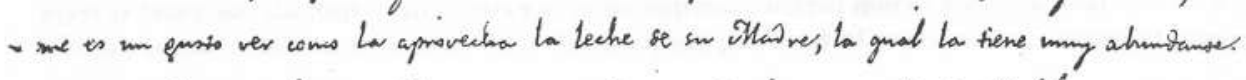

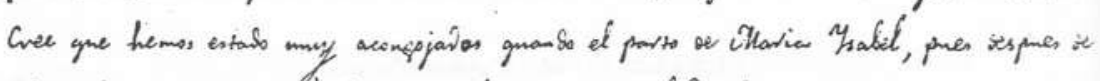

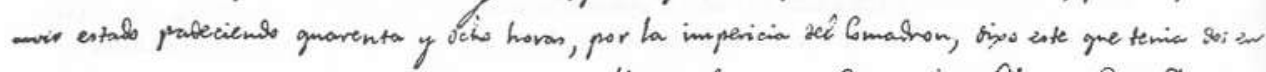

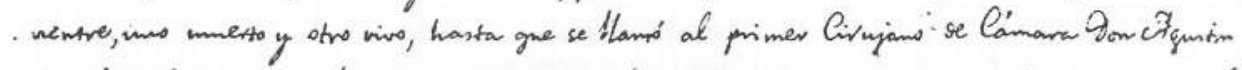

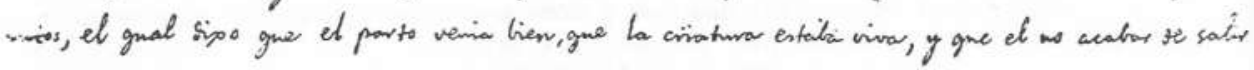

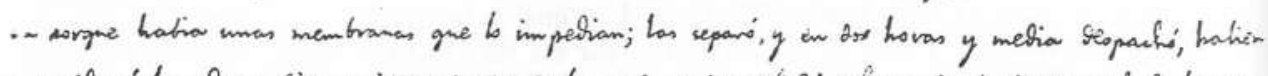

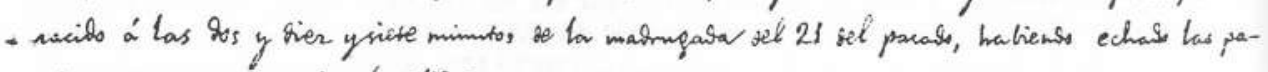

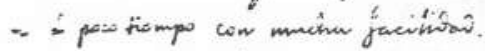

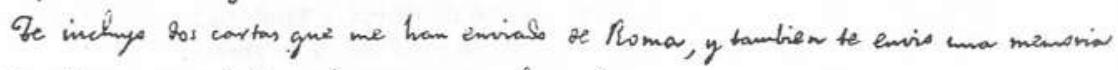

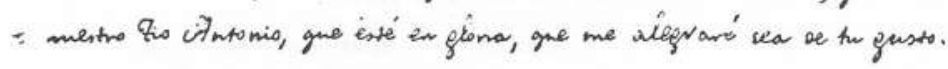

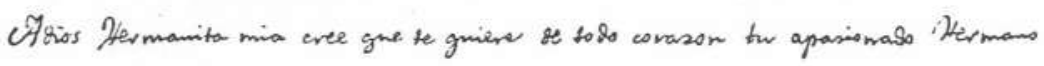


Querida Carlota mia de mi alma, Hermanita mia de mi corazon: he recibido tus dos cartas de 6 de Agosto y 6 de Septiembre, y me alegro estés buena, nosotros tambien lo estamos, gracias á Dios, mi muger de mi alma, que cada dia la quiero mas, y estoy perdido y enamorado de ella esta buena, creimos que estaba otra vez embarazada, pero nuestras sospechas se han desvanecido, pero ella está famosa, mejor que quando se casó, anda mucho á caballo, que la gusto mucho, y yo la acompaño; hoy mismo hemos dado un paseo muy largo, y ella ha trotado y galopado mucho: desde el dia 27 de Julio en que tuve el ultimo accidente no le ha vuelto á dar mas, de modo que puede que se le haya quitado: tuvo que dexar de criar por habersele retirado la leche, por lo qual creimos que estaba preñada: siempre estamos juntos, quando mis ocupaciones me lo permiten, $\mathbf{y}$ estamos muy unidos, y no tenemos mas que una voluntad: la niña es muy bonita, y se ha puesto muy gorda, se habia desmejorado y puesto malita con la mudanza de leche, pero ya se ha repuesto.

No dirás que te olvido, pues siempre me acuerdo de ti, y te amo de corazon como siempre te he amado.

Te incluyo dos cartas, una de nuestra Madre, y otra de nuestra hermana Maria Isabel. La carta que me enviabas para el Santo Padre, se la remití á su Beatitud, y en viniendome la respuesta, te la enviaré.

Adios Hermana mia, creeme que te quiere de todo corazon tu apasionadisimo hermano

\title{
Fernando
}

$[\text { Rubricado }]^{4}$

\author{
Copia de una $[$ sic $]$ \\ parrafo del Periodico \\ el Portugues
}

Extraordinario documento! Solo falta $\mathrm{q}_{\text {. }}^{\mathrm{e}}$ se efectuen los manejos, q. en el se contienen, p. q. veamos sellada la deshonra y la perdic. ${ }^{\text {e }}$ de Portugal, y del Brazil; Funestisimas bodas que amenazan males mas terribles q. las de Creusa con Jason! No; ya nosotros no queremos usar de un timido comedimiento, q. mal se aviene á las crisis desesperadas, ó al tenor de los negocios mas arriesgados; no se debe tratar floxam. asunto q. merece toda energia del escritor; y cuando la honra y seguridad de nuestra Patria peligra, entonces es preciso exercer todo el vigor.

A la verdad, no es el deseo sincero de estrechar los lazos de amistad, y parentezco con un Reino vecino, á razon que mueve á Fernando el agradecido á contraher tales casamientos; no es la razon de estado q. induze al Rei á emplear, en la eleccion de nuestras Princesas, un medio de procrear Fernandos, que succedan en las coronas de España; no es el amor (q. no es pasion q. conoce, como bien lo comprenhendio la Reina $\mathrm{M}^{\mathrm{a}}$. Luiza su madre) quien empele a Fernando a satisfacer una necesidad del corazon; es el miedo, el q. lo lleva á dar este paso; pues reconoce q. no tiene otra ancora de salvac. ${ }^{\mathrm{e}}$, otro piloto q. no sea el q. le venga del Janeiro; es la desesperac. en q. se ve, sin aliados, q. lo sustenten contra el odio de todo su pueblo; en fin, es la necesidad de oprimir álos vasallos con la fuerza de los extranjeros, quitando á aquellos toda esperanza de libertad q. no venga de los esfuerzos de sus brazos: es cierto, pues estos motivos del proceder de Fernando no son poco injustos, p. q. merezcan sacrificios de Efigenias. ¿Que cosa puede mover los consejos de nuestro Principe a concordar con tan ominosas alianzas? A regia estirpe de Fernando? No tiene necesidad de enoblecerse con ella la Augusta Casa de Braganza: que ya está con ella tan entroncada. ¿Querria acaso nuestro Rey, Pedro $1^{0}$ dar una hija al otro Pedro el Cruel de Castilla, mucho menos noble que el bastardo que lo apuñaleo en 
Montiel? Si solo el linage Real en el matrimonio de los Principes se consultase, ¿adónde quedarian el decoro, la honra y la razon de estado? La Austria sacrificó una Princesa á la existencia de la Casa de Habsbourg, amenazada con la ruina por un Conquistador prepotente, la necesidad imperiosa permitio q. la purpura fuese remendada con el basto paño, y q. la ilustrac. ${ }^{\mathrm{n}}$ de los siglos antiguos se desairase con la novedad: mas, ¿que necesidad se puede suponer con el devil Fernando, de hacer sacrificios, iguales por otros lados, á los q. hizo el Emperador Francisco á Buonaparte? Cuando todo el mundo se ha declarado altamente contra el proceder de la Corte de Madrid, q. hace odioso el nombre Real; quando [sic] el del Rey

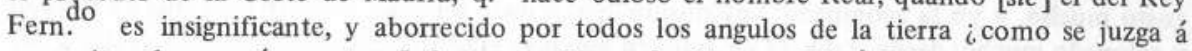
proposito el casar á nuestras Infantas en Espana? Oh, por Dios! Evitese esta vergüenza á nuestro Gov. ${ }^{\text {no }}$, q. ya bastante se ha desacreditado por tratados y alianzas politicas: Fernando $7^{\circ}$ puede casar en Sicilia $(*)$.

Nosotros suponemos q. las arras del casamiento seran la restitucion de Olivenza, y tal vez la adquisicion de algun territorio en los Margenes de la Plata: la restitucion de Olivenza! Que verguenza! Quien nos podia impedir q. una columna de Granaderos fuese á apoderarse de Olivenza? Aun mas: quien podia estorbar al exercito portugues de conquistar ahora toda la España, p. la libertad y para la Augusta Casa de Braganza? Nunca se podia dar ambicion mas justa, ni coyontura tan favorable. Y es con el precio de dos Princesas q. queremos comprar la miserable Olivenza, q. es nuestra, como lo sera tambien toda la España si nuestro Gov. ${ }^{\text {no }}$ lo quisiere? Proh pudor! En cuanto á las cesiones q. se nos puedan hacer en el Rio de la Plata, serian ella iguales a las q. nos quisiese hacer en un rincon de la Siria, otro Rey, q. aun conserva hoy el titulo imprescriptible de Rey de Jerusalen; desengañese Fernando q. su Reino es tanto de las Prov. ${ }^{\text {as }}$ de la Union, como el Reino de Jesucristo era de este mundo: desengañese el Gov. no que la guerra, en q. se empeñe contra los independientes, por no querer recivir las cadenas de Fernando, será la cabal destrucc. ${ }^{\text {n }}$ del Brasil. Tomo nuestro Govierno el acuerdo, y el tono de dignidad q. le cabe; no sacrifique sus dominios americanos á una ruina cierta, por esperanzas dudosas, si no imposibles; y despues de una nota diplomatica, tan impudente, como la de Cevallos ( $\mathrm{q}^{\mathrm{e}}$. en el $\mathrm{n}$. pasado tratamos) no le queda otro desagravio que no sea la fuerza de los suios [sic], en la qual puede poner tanta confianza, como en la flaqueza de los Leones, q. estan agonizando. ¿Hasta cuando desperdiciaremos la buena ocas. que solo se presento á nuestro Rey Emanuel? Un origen comun, habitos y costumbres mui semejantes, la misma religion, fronteras naturales, equilibrio de la balanza de poder, segun el estado publico de la Europa, finalm. la naturaleza fisica y la moral, asi como la politica Europea, estan pidiendo, haze mucho tpo., que baxo una sola cabeza se reuna y concentre nuestra Peninsula, como bajo la de Fernando é Isabel se reunieron las coronas de toda la España. ¿Que seria al lado de este, el Imperio de Alejandro, ó de Trajano? Mas (oh desgracia!) Tal vez estos nuestros avisos tendran la misma suerte q. los de Cassandra. ${ }^{5}$

(*) Si vemos el casam. ${ }^{\text {to }}$ de Fernando $7^{\circ}$ en la casa de Braganza, rebentaremos de dolor, por $\mathrm{q}^{\mathrm{e}}$ no podemos decir como Medea en Seneca,

Acto $1^{\circ}=$ Yo arrancaré de aquella mano impia, la nupcial tea; y su luz al dia. 
Diccivida en $26 \mathrm{sip} \mathrm{p}^{\mathrm{e}}$

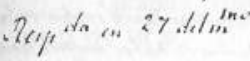
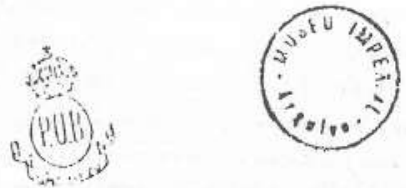

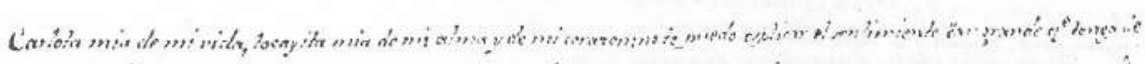

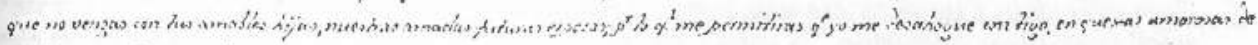

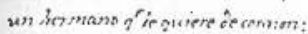

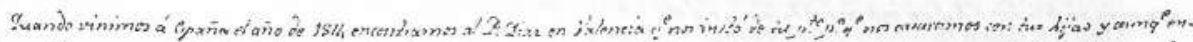

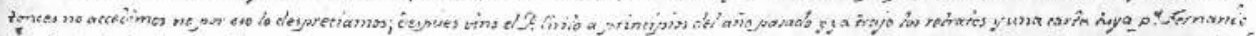

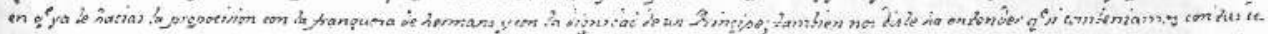

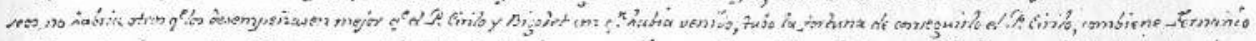

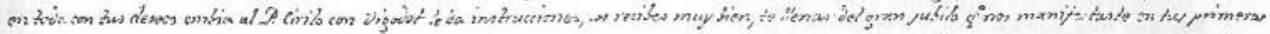

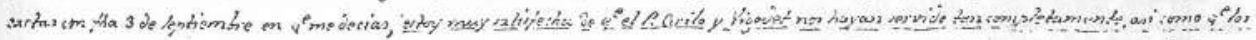

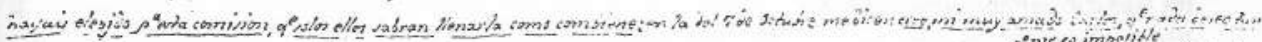

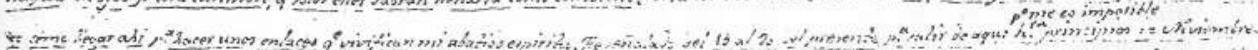
It Dre

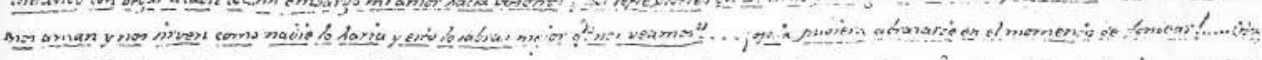

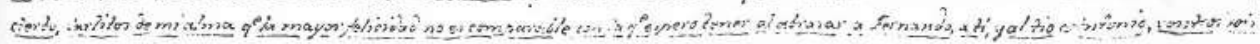

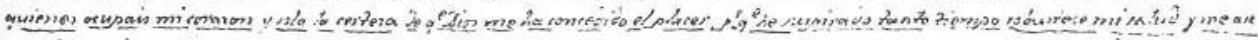

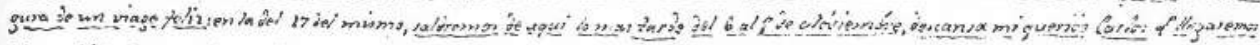

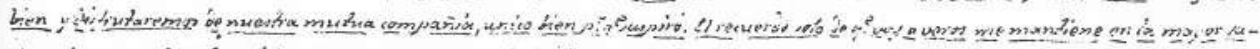

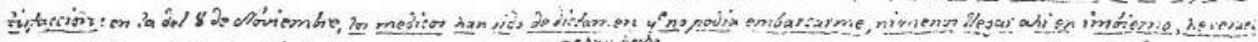

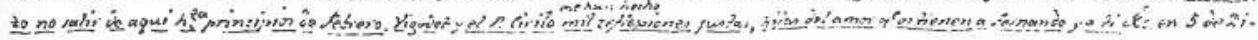

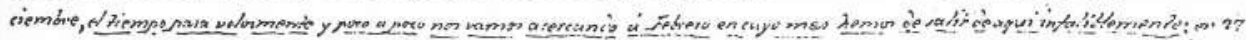

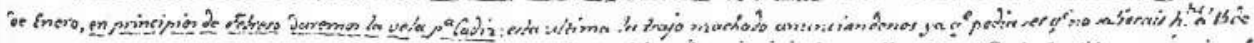

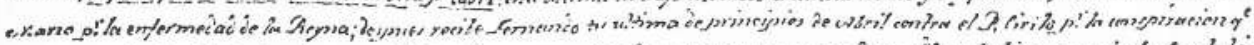

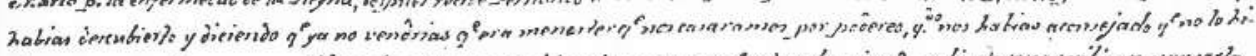

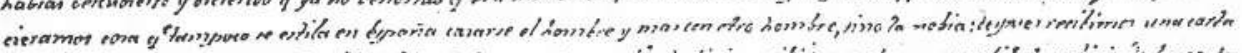

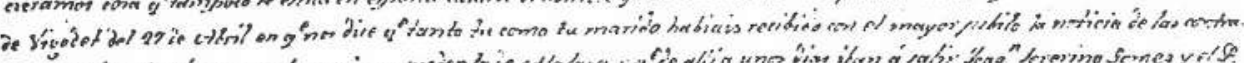

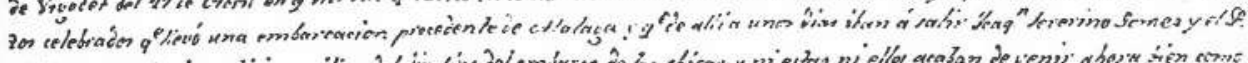

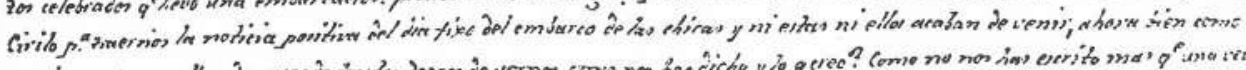

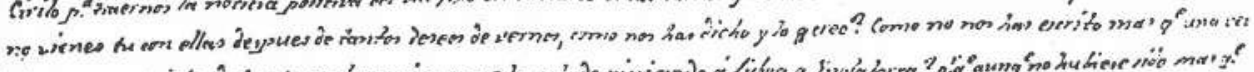

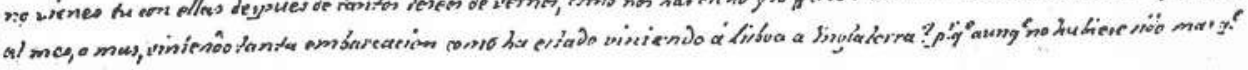




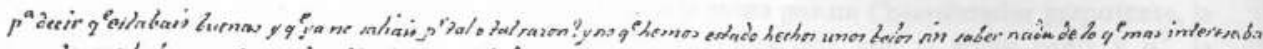

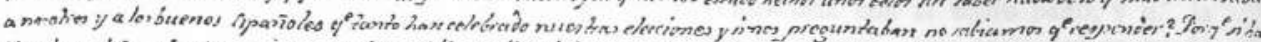

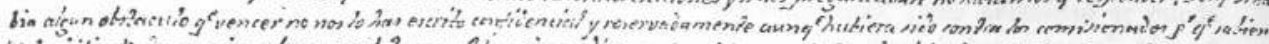

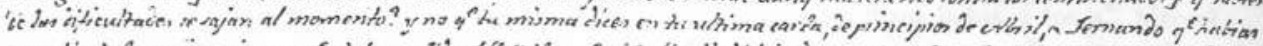

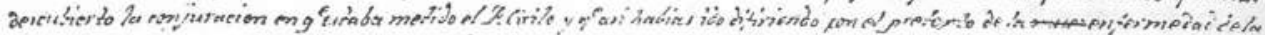

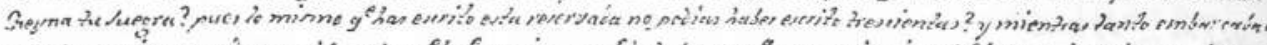

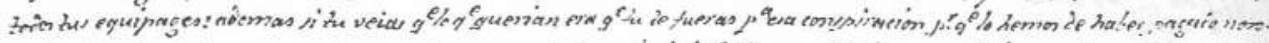

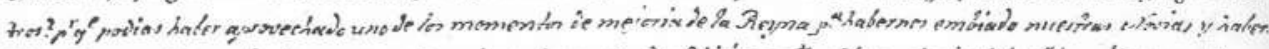

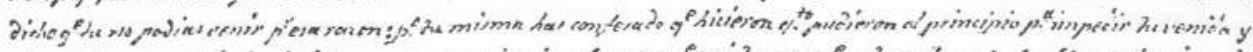

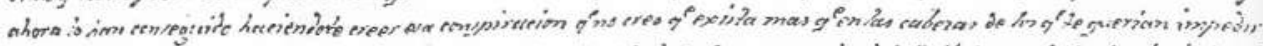

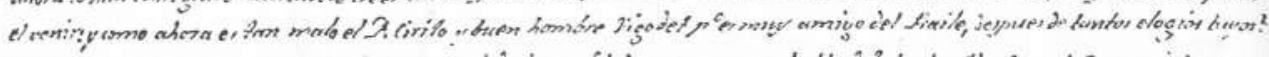

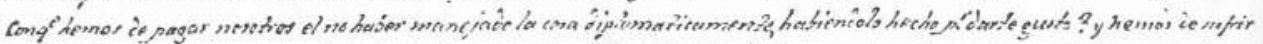

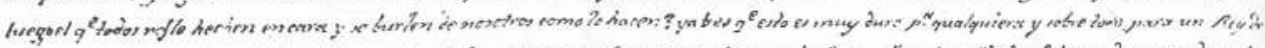

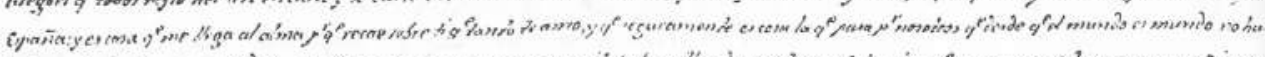

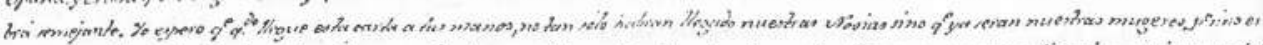

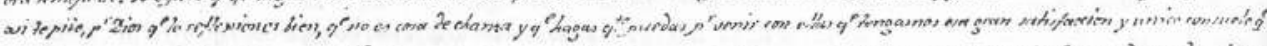

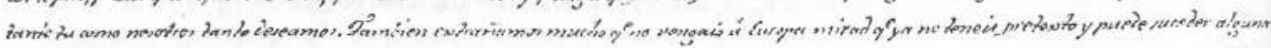

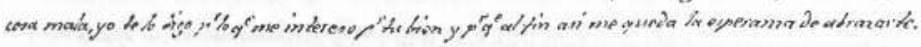

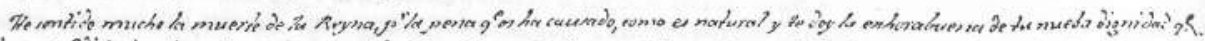

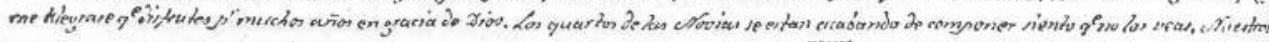

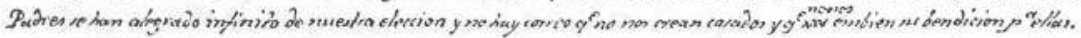

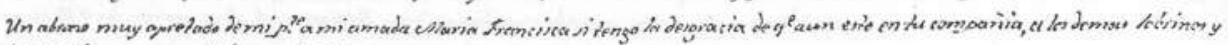

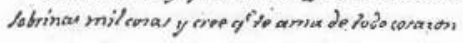
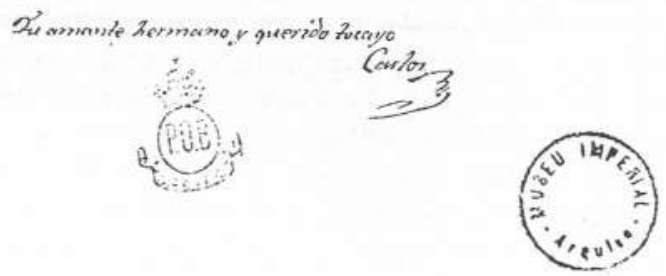
Carlota mia de mi vida, tocayita mia de mi alma y de mi corazon: No te puedo esplicar el sentimiento $\tan$ grande $\mathrm{q}^{\mathrm{e}}$. tengo de que no vengas con tus amables hijas, nuestras amadas futuras esposas; p. lo q. me permitiras q. yo me desahogue contigo en quexas amorosas de un hermano q. te quiere de corazon:

Quando vinimos a España el año de 1814 encontramos al P. Diaz en Valencia q. nos instó de tu p. p. q. nos casaramos cons tus hijas y aunq. entonces no accedimos no por eso lo despreciamos; despues vino el P. Cirilo a principios del año pasado y ya trajo los retratos y una carta tuya p. ${ }^{\mathrm{a}}$ Fernando en $\mathrm{q} .{ }^{\mathrm{e}}$ ya le hacias la propocision [sic] con la franqueza de hermano y con la dignidad de un Principe; tambien nos diste a entender $\mathrm{q} .{ }^{\mathrm{e}}$ si combeniamos con tus deseos, no habria otros q. . $^{\mathrm{e}}$ los desempeñasen mejor q. ${ }^{\mathrm{e}}$ el P. Cirilo y Vigodet con $\mathrm{q} .^{\mathrm{n}}$ habia venido; tubo la fortuna de conseguirlo el P. Cirilo; combiene Fernando en todo con tus deseos embia al P. Cirilo; con Vigodet [cambia ahora la ortografía] le da instrucciones, los recibes muy bien, te llena del gran jubilo q. nos manifestaste en tus primeras cartas con fha. 3 de Septiembre en q. me decias, estoy muy satisfecha de q. el P. Cirilo y Vigodet nos hayan servido tan completamente, asi como q. los hayais elegido p. esta comision, q. solos ellos sabran llenarla como combiene; en la del 7 de Octubre me dices: cree, mi muy amado Carlos, q. nada deseo tanto como llegar ahi p. hacer unos enlaces q. vivifican mi abatido espiritu. He señalado del 15 al 20 del present p. salir de aqui p. me es imposible h. ${ }^{\text {ta }}$ principios de Noviembre contando con llegar a Cadiz [? ] sin embargo mi amor hacia vosotros y las reflexiones del P. Cirilo y de Vigodet me hacen posponerlo todo. Ambos a dos nos aman y nos sirven como nadie lo haria y esto lo sabras mejor q. nos veamos [entre comillas desde el punto] . ... ; ; ojala pudiera abrazarte en el momento de fondear! .... Esta cierto, Carlitos de mi alma q. la mayor felicidad no es comparable con la q. espero tener al abrazar a Fernando, a ti, y al tio Antonio, vosotros sois quienes ocupais mi corazon y sola la certeza de q. Dios me ha concedido el placer p. q. he suspirado tanto tiempo rebustece mi salud y me asegura de un viaje feliz: en la del 17 del mismo, saldremos de aqui lo mas tarde del 6 al 7 de Noviembre, descansa mi querido Carlos q. llegaremos bien y disfrutaremos de nuestra mutua compañia, unico bien p. q. suspiro. El recuerdo solo de q. voy a veros me mantine en la mayor satisfaccion: en la del 8 de Noviembre, los medicos han sido de dictamen q. no podia embarcarme, ni menos llegar ahi en imbierno, he resuelto no salir de $h^{\text {ta }}$ principios de Febrero. Vigodet y el P. Cirilo me han hecho mil reflexiones justas, hijas del amor q. os tienen a Fernando y a ti [? ] en 5 de diciembre, el tiempo pasa velozmente y poco a poco nos vamos acercando a Febrero en cuyo mes hemos de salir de aqui infaliblemente: en 27 de Enero, en principios de Febrero daremos las velas p. Cadiz: esta ultima la trajo machado [sic] anunciandonos ya q. podia ser q. no salierais h. . $^{\mathrm{e}}$ el 15 de Marzo p. la enfermedad de la Reyna; despues recibe Fernando tu ultima de principios de Abril contra el P. Cirilo p. la conspiracion q. habias descubierto y diciendo q. ya no vendrias q. era menester q. nos casaramos por poderes, q. nos habias aconsejado q. no lo hicieramos cosa q. tampoco se estila en España casarse el hombre y mas con otro hombre, sino la nobia: despues recibimos una carta de Vigodet del 27 de Abril en q. nos dice q. tanto tu como tu marido habiais recibido con el mayor jubilo la noticia de los contratos celebrados q. llevó una embarcacion procedente de Malaga y q. de alli a unos dias iban á salir Joaq. ${ }^{\mathrm{n}}$ Severino Gomez y el P. Cirilo p. traernos la noticia positiva del dia fixo del embarco de las chicas y ni estas ni ellos acaban de venir, ahora bien como no vienes tu con ellas despues de tantos deseos de vernos, como nos has dicho y lo creo? [sic] Como no nos has escrito mas q. una vez al mes, o mas, viniendo tanta ambarcacion como ha estado viniendo á Lisboa a Inglaterra? p. q. aunq. no hubiese sido mas q. p. decir q. estabais buenas y q. ya no saliais p. tal o tal razon? y no q. hemos estado hechos unos bolos sin saber nada de lo q. nos interesaba a nosotros y a los buenos españoles q. tanto han celebrado nuestras elecciones y si nos preguntaban no sabiamos q. responder ${ }_{\text {P Porq. }}{ }^{\mathrm{e}}$ si habia algun obstaculo q. vencer no nos lo has escrito confidencial y reservadamente aunq. hubiera sido contra los comisionados $\mathrm{p}^{\mathrm{r}}$. $\mathrm{q}^{\mathrm{e}}$. sabiendo las dificultades se 
sajan al momento? y no q. tu misma dices en tu ultima carta, de principios de Abril a Fernando q. habias descubierto la conjuracion en q. estaba metido el P. Cirilo y q. asi habias ido difiriendo con el pretesto de la enfermedad de la Reyna tu Suegra? pues lo mismo q. has escrito esta reservada no podias haber escrito trescientas? y mientras tanto embarcadas todos tus equipajes; ademas si tu veias q. lo $\mathrm{q}_{\text {. }}^{\mathrm{e}}$ querian era $\mathrm{q}^{\mathrm{e}}$. tu te fueras $\mathrm{p}^{\mathrm{a}}$. esa conspiracion p. q. lo hemos de haber pagado nosotros? p. q. podias haber aprovechado uno de los momentos de mejoria de la Reyna p. habernos embiado nuestras Novias y haber dicho q. tu no podias venir p. esa razon: p. tu misma has confesado q. hicieron q. ${ }^{\mathrm{r}}$ pudieron al principio p. impedir tu venida $y$ ahora lo han conseguido haciendote creer esa conspiracion $\mathrm{q}^{\mathrm{e}}$. no creo q. exista mas q. en las cabezas de los q. te querian impedir el venir: y como ahora es tan malo el P. Cirilo y buen hombre Vigodet p. es muy amigo del Fraile, despues de tantos elogios tuyos? Conq. hemos de pagar nosotros el no haber manejado la cosa diplomaticamente, habiendolo hecho $\mathrm{p}^{\mathrm{r}}$. darte gusto? y hemos de sufrir luego q. todos nos lo hechen en cara y se burlen de nosotros como lo hacen? ya ves q. esto es muy duro p. qualquiera y sobre todo para un Rey de España: y es cosa q. me llega al alma p. q. recae sobre ti q. tanto te amo, y q. seguramente es cosa q. pasa p. nosotros q. desde q. el mundo es mundo no habrá semejante. Yo espero q. q. llegue esta carta a tus manos, no tan solo habran llegado nuestras Novias sino q. ya seran nuestras mugeres p. sino es asi te pido, p. Dios q. lo reflexiones bien, q. no es cosa de chanza y $\mathrm{q}_{\text {e }}^{\mathrm{e}}$ hagas $\mathrm{q}^{\text {to }}$ puedas $\mathrm{p}$. venir con ellas $\mathrm{q}^{\mathrm{e}}$. tengamos esa gran satisfaccion y unico consuelo q. tanto tu como nosotros tanto deseamos. Tambien extrañamos mucho q. no vengais á Europa mirad q. ya no teneis pretexto y puede suceder alguna cosa mala yo te lo digo p. 10 q. me intereso p. tu bien y p. q. al fin asi me queda esperanza de abrazarte.

He sentido mucho la muerte de la Reyna, p. la pena q. os ha causado, como es natural y te doy la enhorabuena de tu nueba dignidad q. me alegrare $\mathrm{q}^{\mathrm{e}}$. disfrutes $\mathrm{p}$. muchos años en gracia de Dios. Los quartos de las Novias se estan acabando de componer siento q. no los veas. Nuestros Padres se han alegrado infinito de nuestra eleccion y no hay correo q. no nos crean casados y q. no nos embien su bendicion p. ellas.

Un abrazo muy apretado de mi p. a mi amada Maria Francisca si tengo la desgracia de q. aun este en tu compañia, a los demas sobrinos y sobrinas mil cosas y cree qe te ama de todo corazon

Tu amante hermano y querido tocayo

Carlos

[Rubricado $^{6}$

\author{
Department of Romance Languages \\ Wake Forest University \\ Wiston-Salem, N.C. - USA
}




\section{NOTAS}

${ }^{1}$ Fernando pide a su hermana en esta carta que, como española amante de su patria y hermana suya, influya para que los portugueses abandonen sus conquistas. Necesitando ayuda una vez más, el monarca español confía que su hermana no se olvidará de España ni de un hermano que tanto la quiere; amor que olvidará cuando las circunstancias sean otras. Pero Carlota, que no se dejaba intimidar fácilmente, contestó a Fernando el 6 de agosto de 1817: "Hijo mio, ya te tengo dicho, que yo ni activa ni pasivamente podía hacer ni influir sobre las cosas de tus Dominios del Rio de la Plata; en el alma no siento, y aun mas el tener que volver a repetirlo, para que veas el mejor y mas prudente modo de tratar de este particular con quien pueda desenvolver el emblema, que no puedo acabar de entender." Esta carta se encuentra en el folio 6, vuelta, del Libro de Registro Secreto que Carlota guardaba referente a los negocios de América. Se encuentra en el archivo particular de S.A.R. el Príncipe D. Pedro de Orleans y Braganza, de cuya repetida hospitalidad y cortesía seré siempre deudor. Ver sobre esta invasión el artículo de Enoch Resnick, "Spain's Reaction to Portugal's Invasion of the Banda Oriental in 1816," RHA, núms. 73-74 (julio-diciembre, 1971), 131-43.

${ }^{2}$ A esta carta contestó Carlota el 21 de setiembre de 1817: "Querido Fernando mio de mi alma. He recibido tu carta de 20 de Abril, que me entregó Casaflores, en que me respondes a las mias, y me ha sido de mucha satisfacción por ver letras tuyas; $y$ voy a responder a varios artículos de ella $=$ Primeramente tu me dices, que no es por falta de cariño, que me dejas de escribir, sino por falta de tiempo, y porque tenia noticias tuyas por Maria Isabel: Hijo mio, quien quiere siempre tiene tiempo, y tu hasta ahora siempre lo tuvieste; $;$ solo ahora es que te falta tiempo? Aprovechalo bien que ya llega para todo; y la Maria Isabel escribiendome cumple con su obligacion, porque es mi hija, y yo nunca pierdo el derecho de Madre, para que ella me trate siempre con el amor y respeto que debe, porque por estar casada no la dispensa de las obligaciones de hija = Segundo, te agradezco infinito el redondo desengaño que me das respecto a los Casamientos de mis hijas, y del negocio del tabaco, y queda muy satisfecha mi alma, y tambien mi pundonor, de haber sacrificado por todos modos mi sosiego, mi salud, y todos mis intereses (como todos lo saben) solo por el amor que te tengo; pues mis miras siempre fueron, son y seran (si Dios no me desamparase) desinteresadas, y rectas; y no para perjudicarte a ti, ni a nadie, ni para fastidiarte; por tanto, da todo lo dicho por no dicho; pues yo no quiero que me des un alfiler, ni que concurras para mi descanso, ni nada: pues quiero morir con la satisfaccion de que me desvele y sacrifique por ti, y que tu me pagas con ingratitud; y que esto conste en todas partes del mundo, y para la posteridad, hasta el fin de los Siglos. Te prometo, que no es mi boca, ni mi pluma quien lo ha de publicar, porque no es mi caracter, ni mi amor para contigo me lo permite $=$ Fernando mio, vuelvo a decirte que los intereses no son nada para mi, porque quien supo quedarse casi sin camisa, sabe despreciar todos cuantos intereses hay y pueda haber en todo el mundo; pero todo lo que toca a mis hijas me duele y hiere hasta lo mas intimo de mi alma: y estoy bien cierta, que si tu te vieses en mis circunstancias que te alegrarias ver a tus hijas bien acomodadas $=$ Adios Fernando mio, se mas consecuente con quien te ama de veras como esta tu hermana $=$ Carlota Joaquina." Libro de Registro Secreto, folio 11, vuelta.

${ }^{3}$ Los documentos reproducidos hasta aquí se encuentran en el Archivo Imperial del Brasil. (Petropolis), II-POB-17.4.815-F.VII.E.c 1-7.

${ }^{4}$ Ibid., I-POB-2.4.816-F.VII.E.c 1-4.

5 Ibid., I-POB-6.4.816-Vil.c 1-3.

${ }^{6}$ I-POB-26.1.816-C.E.c 1-6. Reproduzco aquí esta carta del hermano de Fernando por tratar del mismo asunto y porque nos da una buena idea de su autor. 